\title{
Achieving Transport Efficiency Through The Architectural Design of A Multimodal Transport Terminal In Greater Port Harcourt City.
}

\author{
Baridakara Igbara $^{\mathrm{a}}$, Enwin Anthony Dornubari ${ }^{\mathrm{b}}$ Simeon Igbara $^{\mathrm{c}}$ \\ a igbarabaridakara@yahoo.co.uk \\ ${ }^{a}$ Department of Architecture, Faculty of Environmental Sciences, Rivers State University, Port Harcourt, 500272, Nigeria \\ ${ }^{a}$,Department of Architecture, Faculty of Environmental Sciences, Rivers State University, Port Harcourt, 500272, Nigeria \\ ${ }^{c}$ Department of Estate management, School of Environmental Sciences, Ken-Saro Wiwa polytechnic, Rivers State, 500272, Nigeria
}

\begin{abstract}
This study reviews the current state of the transport system in Port Harcourt with a view to incorporate a workable multimodal terminal in greater Port Harcourt City. The study highlights that the existing transport system in Port Harcourt still grapples with problems of uncoordinated or poorly maintained public transport infrastructures, proliferation of illegal parks as well as the general deterioration of existing public terminals. Furthermore, there are no specific transport link between the water, road and rail transport network to allow ease of movement of people and goods across the transport modes. The study reviewed existing multimodal terminals in terms in functionality, circulation, spacing and the overall contribution to the transport system. It was found that the multimodal terminals provided a seamless, gapless and cost-effective transport operations which gives transport users maximum flexibility to decide for themselves on the optimum use of combination of different modes in transportation of freight. Hence, the study recommends the design and implementation of functional and aesthetically pleasant multimodal terminal that seeks to drive ease of movement of goods and services, comfort, convenience and contemporary travel experience amongst road and rail commuters in Greater Port Harcourt. With Port Harcourt city being one of the major hubs of economic activities south of Nigeria, the development of a multimodal terminal as well as the overall development of the multimodal transport will help increase the quantum of economic activities and living standards.
\end{abstract}

Published by IJRP.ORG. Selection and/or peer-review under responsibility of International Journal of Research Publications (IJRP.ORG)

Keywords: Multi Modal; Transport; Terminal; Movement; Comfort.

\section{Introduction}

An effective and convenient transport system with emphasis on connectivity and functionality of the maritime, rail, road and rail is a strong boost for economic growth and development of any nation (Oyesiku, 2013). This draws from the fact that a good transportation network is a strong motivator of economic activities through the improvement accessibility and the facilitation of the movement of goods and services to different parts of the country. Transportation system ensures successful movement of passengers, cargoes, and mails from one point to another for social purpose, economic purpose or spatial purpose through different modes such as unimodal, bimodal or multimodal (Good, 2015). The integration of the various modes of 
transportation provides significant benefits in terms of sustainability (Innocent, 2011), regional integration (Oladipo, 2012), improved logistics (Gigado, 2015) reduced costs and improved efficiency (Debela, 2013) amongst others. However, it is regrettable that these modal integrations are yet to be fully domesticated in Nigeria as the nation still grapples with issues in infrastructural investments, concentrating more on singular modes of transportation without proper integration.

Ogunbodede (2008) asserted that transportation in Nigeria is dominated by the use of the road network almost making it unimodal. This is due largely to the large investment considerations given to the system when compared to investment in railways and maritime. In view of this, Oladipo (2012) asserted that the neglect of other modes of transportation have largely favoured the road investment in Nigeria. The obvious outcome of this is the imbalance in the transport sector as experienced in the country where more than ninety percent of movement of either goods or commuters are done through the road networks (Oladipo, 2012). Current transport operations are characterized by large-scale movements of goods and passengers that could have been moved more cost effectively by other modes, such as railways and inland waterways.

Multimodal Transport system has been found to provide seamless, gapless and cost-effective transport operations which gives transport users maximum flexibility to decide for themselves on the optimum use of combination of different modes in transportation of freight across the country (Etu and Oyedepo, 2017). With the flexibility of switching through different modes within a single terminal, commuters, goods and services can be interchanged with a reduced cost and time as well as with better efficiency. Recent studies in Nigeria reveal that although the policies of a multimodal transport systems with its objectives such as seamless, gapless and cost effective transport operations are embedded in the Nigeria national transport policy of 2004, inadequate/lack of infrastructures to support it, absence of requisite regulatory frame work and overdependence on roads as a mode of transportation among other issues has been responsible for its ineffectiveness (Odeleye, 2015).

With the increasing urbanization as well as physical and economic development in Port Harcourt, there is the need to balance the gap between demand and supply of transport system which is an integral part of economic growth. In view of this, a good transport system is necessary for the present and future scenario. It follows therefore that the importance of the Multimodal transport facility in the transport system becomes especially important as the existing transport facilities within Rivers State is not capable of meeting the demands of the day. Anecdotal evidences reveal that existing terminal building in Port Harcourt lack the basic amenities, facilities and services necessary for functional and effective transport experience. The architects and designers rather focus on the structures aesthetic form instead of focusing on the functional flow of the building and its useful spaces. Evidently, most terminals reflects lack of proper organization which is one of the major problems of the Nigerian transport industry. Consequently, this part seeks to unravel the prospects of fully domesticating a multimodal terminal in Port Harcourt with a view to improving the transport situation in the city.

\subsection{Problem Statement}

A glimpse at the current transport situation in Port Harcourt reveals several spots of public and privatelyowned terminals with little or no attention to functionality, circulation or the comfort of commuters. These are compounded by the presence of numerous illegal parks and terminals which creates an avenue for several social vices as well as degrade existing city character. There is the problem of uncoordinated and poorly maintained public transportation, to the extent that so much emphasis is laid on the road development to the disadvantage of other existing modes of transportation - surface rail and ferry transportation. Existing rail 
terminals within the city are either localized or in a deplorable and undesirable state. Very little attention is placed on improving the quality of rail infrastructure terminals within the city. Also, there is no specific transport link between the water, road and rail transport network to allow ease of movement of people and goods across the transport modes. Commuters still grapple with the draconian task of incurring additional expenses or having to use localized means to move goods from one mode of transport to the other.

If all these problems are not put in place, Port Harcourt will unfortunately continue with the excessive use of roads and the associated negative consequences which include rapid deterioration of roads, high accidents rates, inefficient intermodal freight split, amongst other inefficiencies. Several concerted efforts have been made by both the government and private institutions to stem the tide in travel experience but these efforts are greeted maladministration, abuse or in some cases, shanty construction or poor architectural considerations. Hence, this study is saddled with the problem of designing a functional and aesthetically pleasant multimodal terminal that seeks to drive ease of movement, comfort, convenience and contemporary travel experience amongst road and rail commuters in Port Harcourt.

\subsection{The Study Area}

The study was conducted in Port Harcourt Metropolis of Rivers State, Nigeria. The study area is influenced by urbanization or urban sprawl whereby smaller communities have merged together and form a megacity. This is due to high influx of people resulting in a rapid growth of the population in the study area. This in turn is largely due to the expansion of the oil and allied industries which have also attracted many varied manufacturing industries. The relief is generally lowland which has an average elevation of between $20 \mathrm{~m}$ and $30 \mathrm{~m}$ above sea level. The geology of the area is basically comprised of alluvial sedimentary basin and basement complex. The vegetation found in this area includes raffia palms, thick mangrove forest and light rain forest. The soil is usually sandy or sandy loam underlain by a layer of impervious pan and is always leached due to the heavy rainfall experienced in this area.

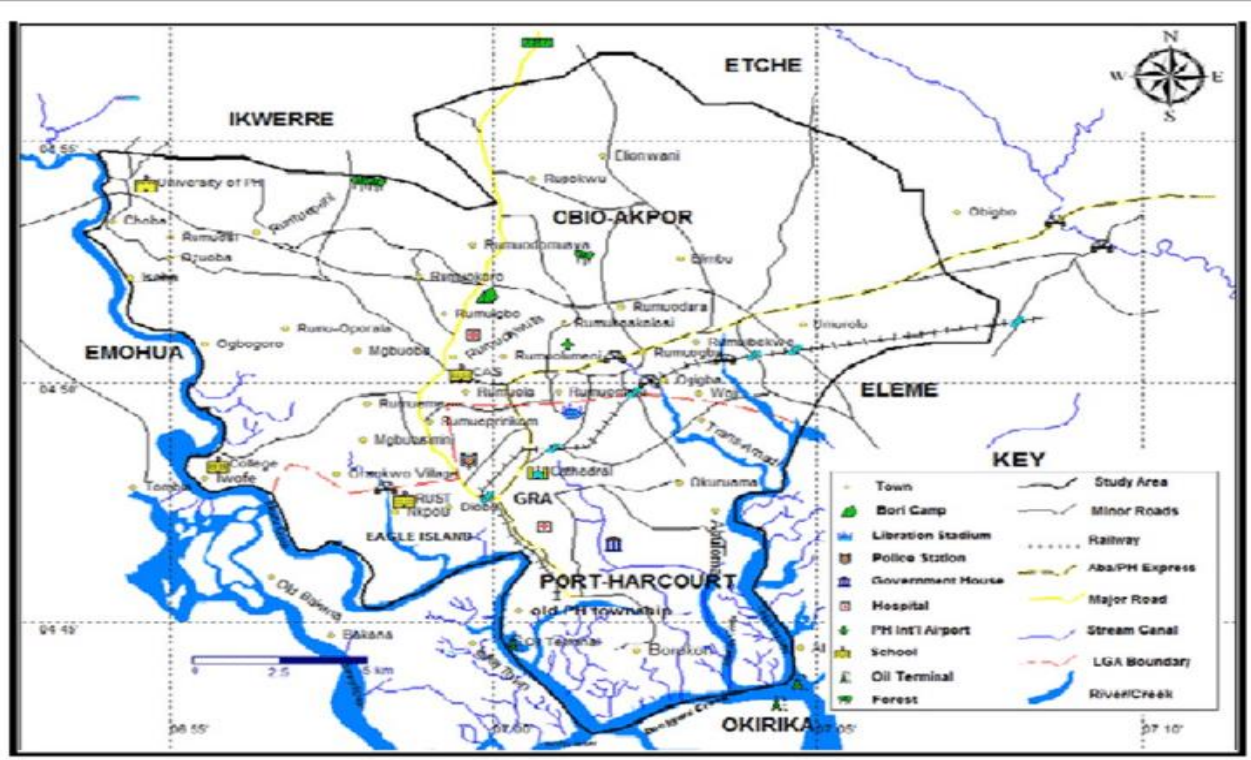

Fig. 1: Base Map of Port Harcourt Metropolis

The study area is well drenched with both fresh and salt water. The salt water is caused by the intrusion of sea 
water inland, thereby making the water slightly salty. Due to continuous heavy rainfall and river flow, the study area experiences severe flooding almost every year and the effects are extended to biological resources. The city was chosen as the study area.

\subsection{Review of Existing Transport Situation in Port Harcourt}

In order to properly domesticate the multimodal transport system in Port Harcourt, an assessment of the current state of the various modes of transportation in Nigeria in a holistic and coherent manner is essential. These are highlighted below:

\section{a). Rail}

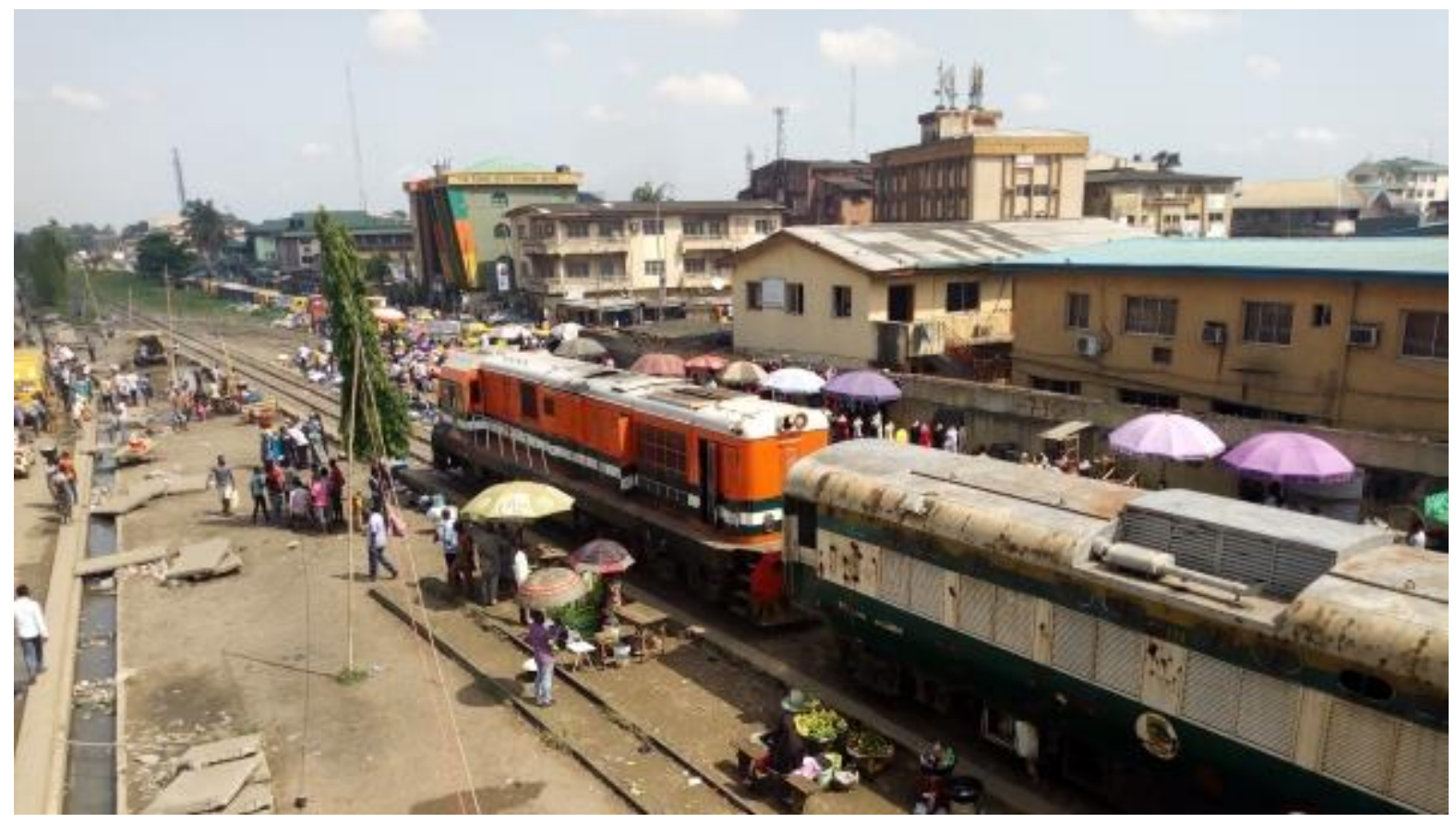

Plate 1: Typical Rail Line in Port Harcourt

The railway system in Port Harcourt has been fraught with several challenges that are worth mentioning. These issues are quite synonymous with what is obtainable in other parts of the country. Some of these challenges include technical problems such as poorly constructed tracks, undulating terrain, poor management culture, indiscipline, etc.(Adesanya, 2010). Abioye et a.l, (2016) explained that these problems are further complicated by the gross underfunding/neglect of rail system for road transport development by government, falling rolling stock levels/shortage of locomotives, Plummeting traffic levels (freight and passenger) and loss of patronage to the road transport sector. 


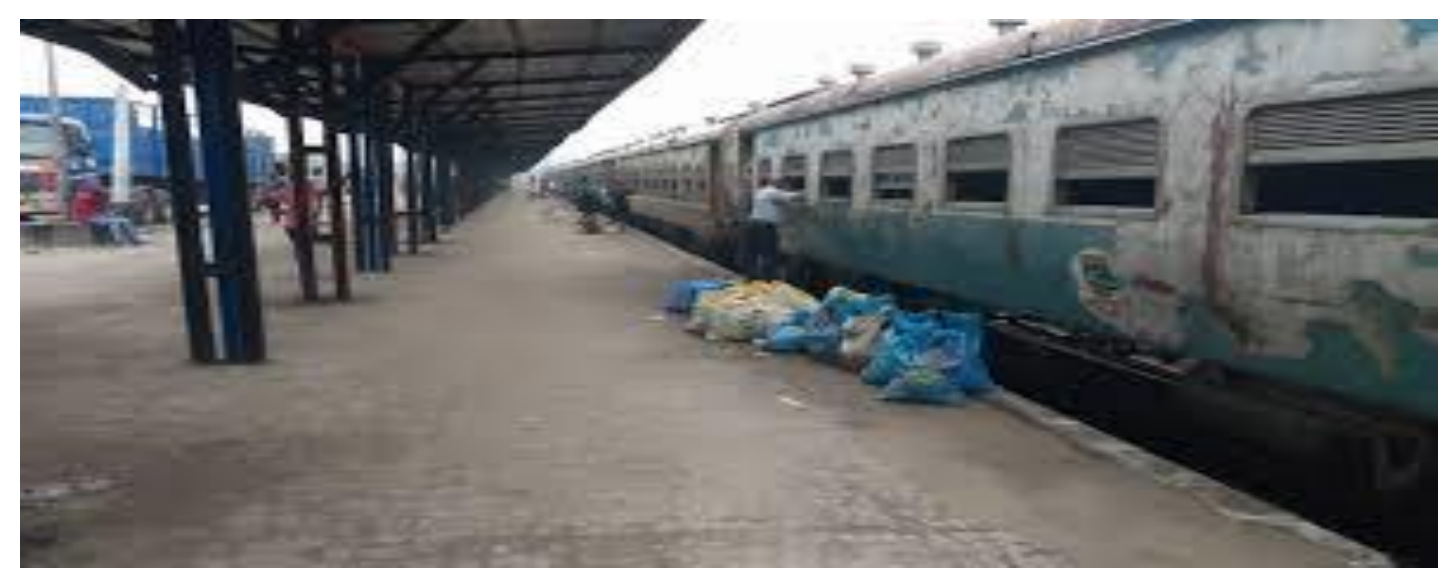

Plate 2: Typical Rail Terminal in Port Harcourt

Other issues in rail transportation include worn-out infrastructure, Lack of maintenance, weak and Lack of political commitment in implementing and meeting the timelines for plans and programmes. Ademiluyi and Dina (2011) explained that there has been a rise in rail accidents in Nigeria since the start of its revival due to poor safety measures. In Port Harcourt, it is uncommon to find traders display their wares across the rail lines and people cross the rail lines without caution, which has led to the death of some individuals.

\section{b). Road}

The road transport in Port Harcourt is faced with a multiplicity of challenges. Although recent efforts of government have been geared towards improving the road conditions through flyovers, interchange, etc., other specific issues still stand out. There are lack of sufficient parking spaces and this have led to issues such as the proliferation of onstreet parking as well as the prevalence of illegal parks. The lack of effective regulation on parking has deepened the parking situation in the city.

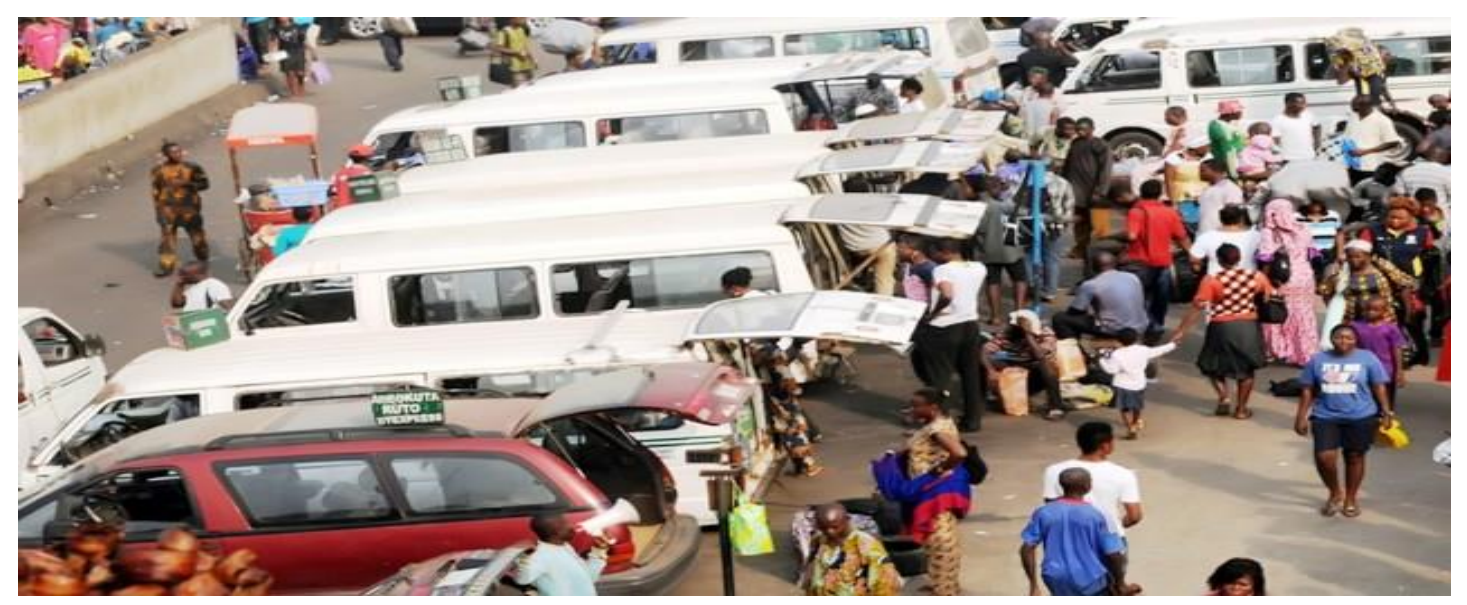

Plate 3: Illegal bus terminals in Port Harcourt. 
Generally, the road transport mode which is the dominant mode of transportation in Port Harcourt has shown a largely inadequate state of infrastructure coupled with undue pressure of freight movement on the roads. It has also been seen that the roads are mostly in deplorable states thereby leading to delays, accidents and diverse problems in transit.

\section{c). Maritime}

Port Harcourt is best described as a coastal city but the inland waterways have been grossly underutilized in terms of freight and commuting. This is largely due to the non-integration of the transport mode with other modes of transportation.

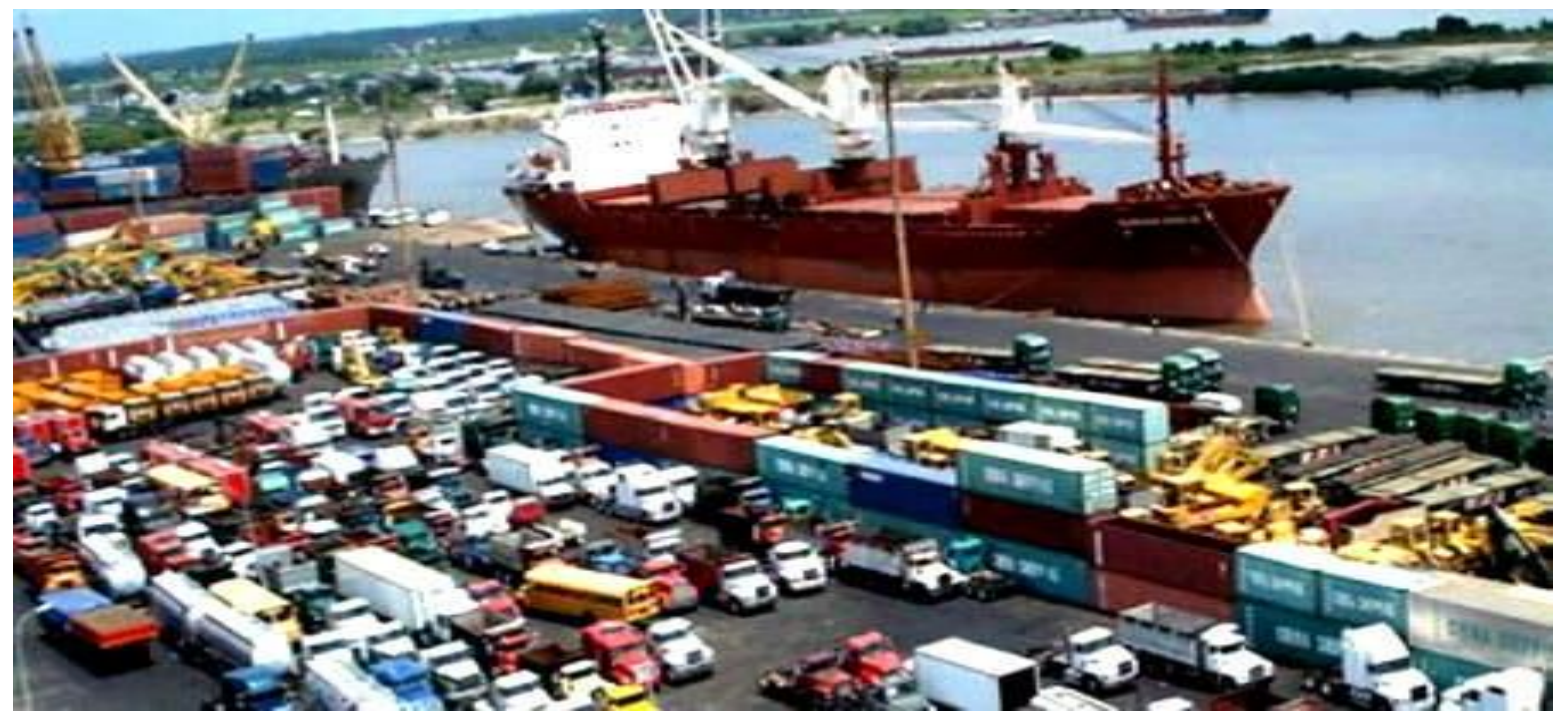

Plate 4: Port Congestions in Port Harcourt.

Existing port in the city is fraught with issues of congestions largely due to the presence of numerous containers and trucks, thus affecting the overall efficiency of the transport mode. This situation would be best resolved through multimodal means of containerization via rail transport lines.

\section{d). Air}

In terms of cargo movement, the Port Harcourt airport underperforms in comparison to other airports in the country. Data from the aviation sector show that of the five international airports in the country between 2007 and 2011, MMA, Lagos accounted for about $90 \%$ of the cargo handled at the Nigerian airports. This concentration on a particular airport can be said to be the cause of regular delays and unsatisfactory performance of these services.

The Concept of Multimodal Transportation has been prevalent in extant literature on transportation studies. The concept has evolved as a result of the need for more integrative means of transportation to ease 
movement of people and cargo in a more efficient and sustainable manner. Multimodal transportation according to The United Nations Convention on Trade and Development (UNCTAD, 1981) was defined the concept of 'Multimodal Transport' as: "the carriage of goods by at least two different modes of transport on the basis of a multimodal transport contract from a place in one country at which the goods are taken in charge by the multimodal transport operator to a place designated for delivery situated in a different country". This definition however focuses on the international trade benefits of multimodalism between different countries.

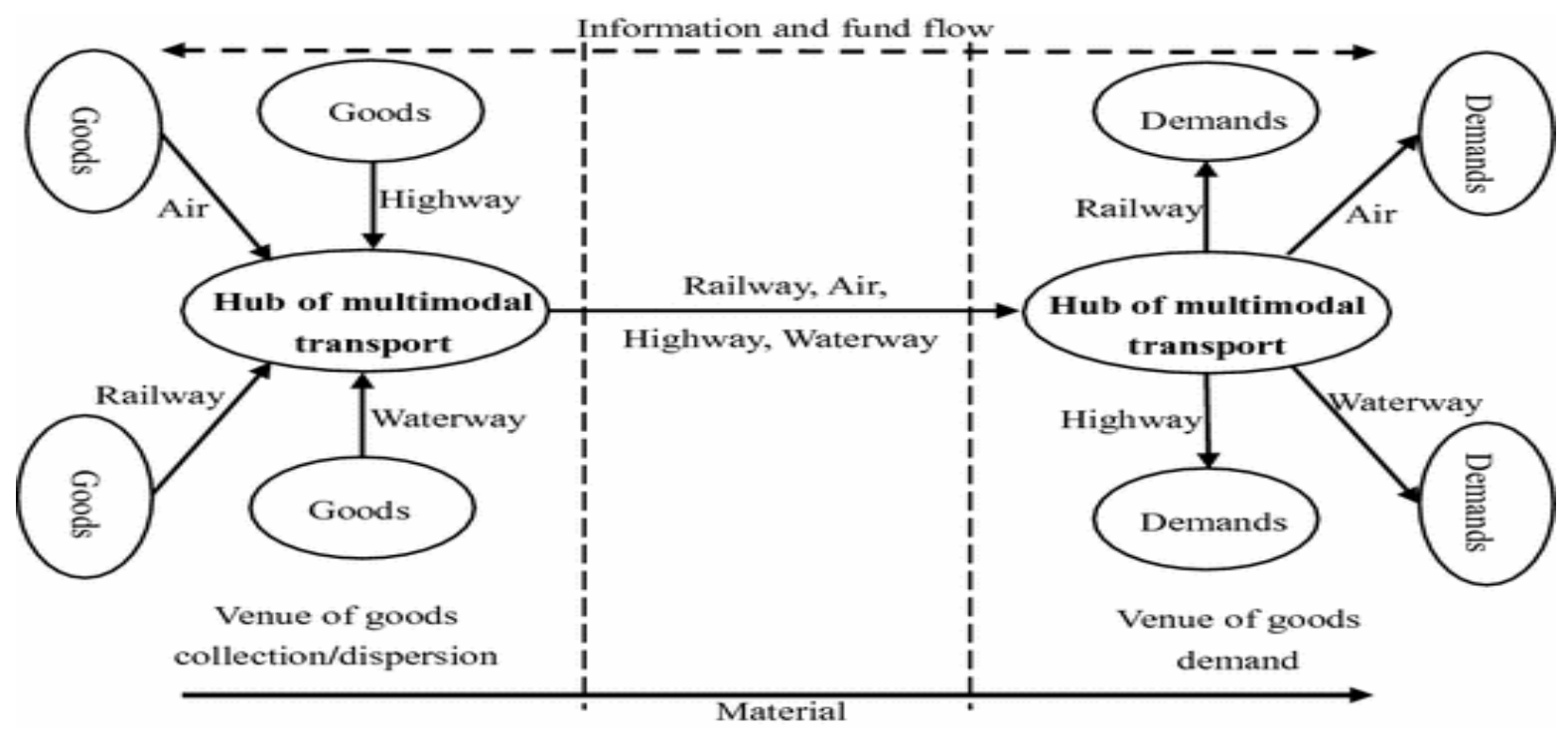

Fig. 2: Multimodal Transport Model

Source: Adapted from Xiao J., Liu X. (2018)

However, more localized concept of multimodal transport has evolved to mean system of seamless, gapless and cost-effective transport operations which gives transport users maximum flexibility to decide for themselves on the optimum use of combination of different modes in transportation of freight across the country or between countries (Etu and Oyedepo, 2017). The concept of multimodal transport according to Xiao J., Liu X. (2018) is premised on the fact that a a product is brought from the door of its source, the manufacturer, to the door of its demand, the end user, by making use of at least two modes of transport, which is also commonly known as the door-to-door service (as shown in fig. 2).

\subsection{The benefits of multimodal transport system}

The benefits derivable from the multimodal operations are far reaching. In emphasizing these benefits, Janic (2008) stated that "multimodal freight transport has been considered as the most prospective, competitive and environmentally friendlier alternative to unimodal road freight transport in medium to long distance corridors". This is because of the advantages it brings in terms of the cost of transporting goods across various modes as well as the time saving opportunities of the multimodal system.

The multimodal system of transportation is a system which covers various modes of transport and has the 
potential to contribute to a cleaner, smarter and more sustainable transport, shifting mobility of passenger and goods from road, making optimal use of infrastructure and reducing costs (Etu and Oyedepo, 2017). In highlighting these essential benefits of multimodal transport, Reis (2015) provided a framework for capturing the benefits of multimodal transport across different levels (See Fig. 3 below)

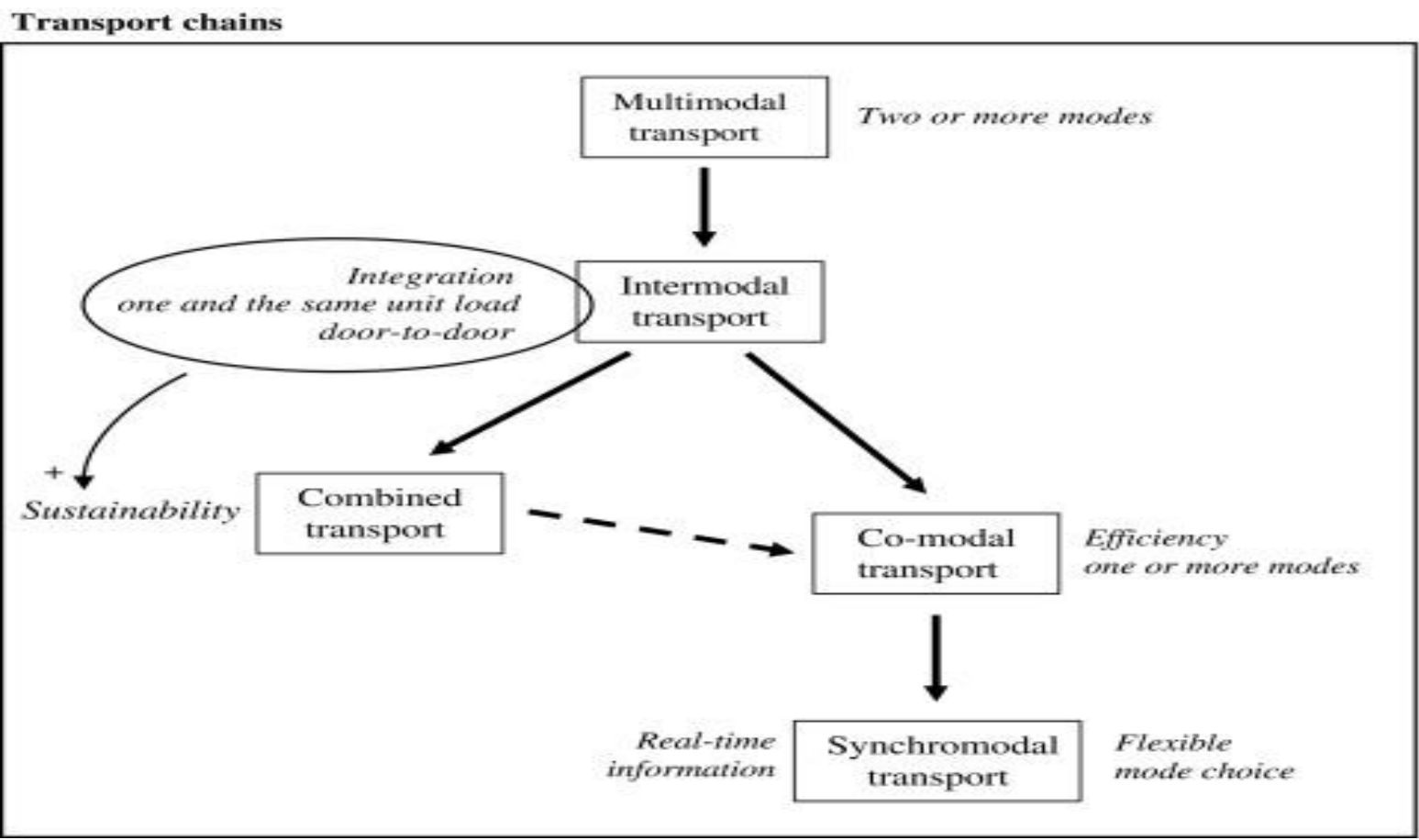

Fig. 3: Benefits of multimodal Transport System Source: Adapted from Reis (2015)

\subsection{Multimodal Terminals as a Prerequisite to successful multimodal Implementation}

Successful implementation of any transport systems requires a good investment in terminals or stations. Transit stops, stations, and terminals provide particular services for a transit system. Among station types and configurations, multimodal terminals are the focus of this study. Multimodal terminals are defined as "a variety of stations and terminals that provide key transfers between transit modes. Combinations may include local bus, bus rapid transit, intercity bus, light rail, heavy rail, commuter rail, intercity passenger rail, ferry, or automated guide way transit. Such facilities may have a variety of other services and connections, including parking, drop-off, and ticket vending and information booths and may be integrated with retail shopping, services and entertainment" (Transport research board; 2003).

Multimodal terminals are of key importance in transport as they serve the complex transportation network of the multi-lines and multi modes of transportation, and they also have a high position within business and consumption, reflected by the intensive and diverse attractions of restaurants, shops and services points inside the station. In addition, existing requirements on terminal design suggests that a functional station requires 
different circulation spaces for travelers (Fernandez et al., 2010). Terminals should also have simple, obvious, and comfortable circulation patterns, since a logical station plan and inner arrangements help greatly to make the trip inside the station clearer and easier to navigate. Consequently, providing relevant services, fitting them properly are key issue in the design of properly functioning stations, all arrangements together should provide sufficient space to allow smooth flow of travelers through stations (Etu and Oyedepo, 2017).

\subsection{Review of Case Studies on existing multimodal terminals}

\section{a. Gothenburg, Sweden}

Gothenburg multimodal station is formed by three connected buildings; the Central Station, the Central house, and the Nils Ericsson terminal. The station as a whole acts as a convergence node for multi-lines and multi modes of transportation; Passengers come from local buses, long-distance buses, trams, local trains and long distance trains, taxi and private cars.

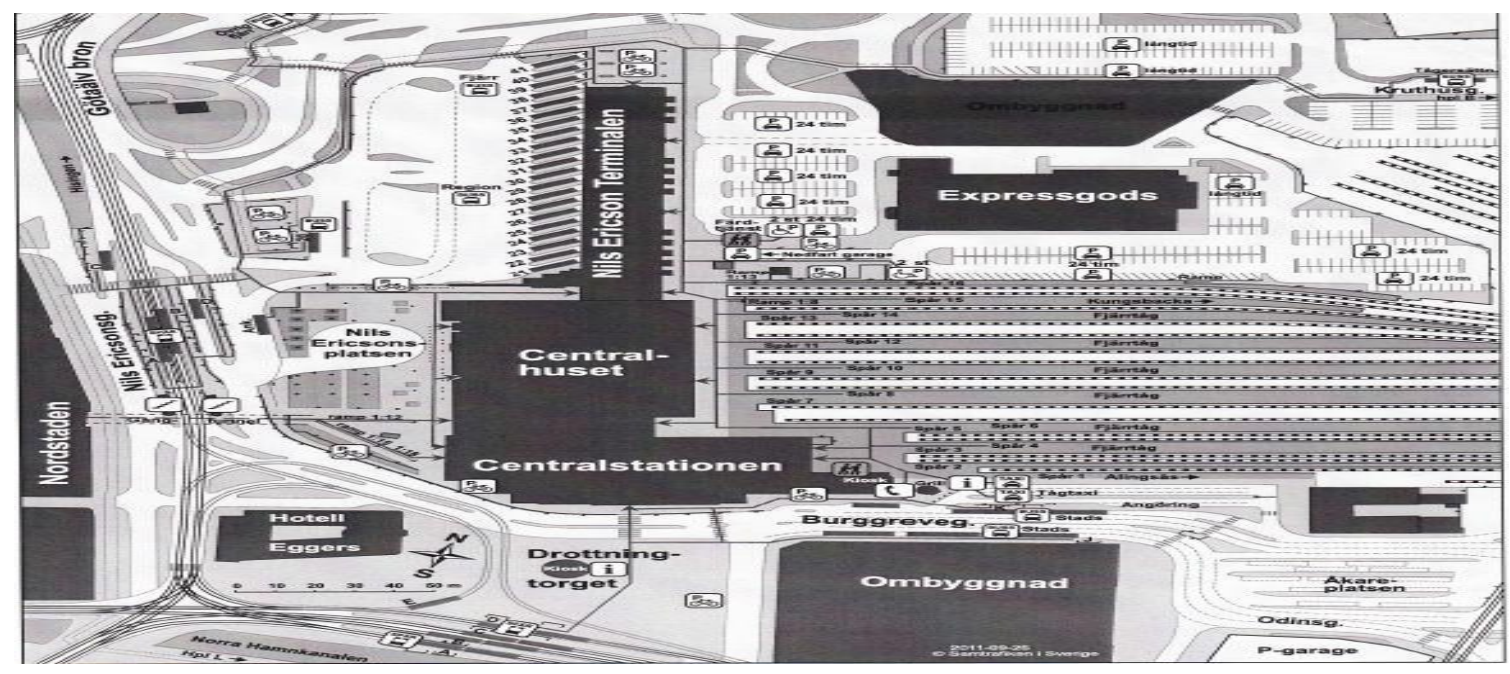

Fig 4: Gothenburg Central Station

Source: Trafikverket, (2012)

The station ownership structure is fragmented; the Nils Ericsson terminal is owned and operated by Västtrafik, which operates the bus services in the region. The central station and the central house are owned and managed by Jernhusen; a real estate company in transport business, which on a commercial basis own, develop and manage the station area (Jernhusen, 2012), and the tracks are owned by Trafikverket. This typically domesticates the value of Public-Private Partnership in the delivery of capital projects.

The terminal does not only serve the transport needs of commuters but also aim to create a meeting point in the station, i.e., increase its place value within the region (Jernhusen, 2012). In this perspective, the development schemes link travelers' services with commercial activities, shops and restaurants, creates enjoyable and efficient environment. Creating the terminal as a destination in itself contribute to the aim of doubling the public transport, as even if people don't want to travel, they still can use the station as a hub and a place to meet 
The terminal provides a good balance between the train and bus transport means, thus, improving efficiency within the two transport means. As for trains, there are sixteen train tracks, divided between the central station building (from track number 1 until track number 4), and the central house (from track number 5 until track number 16). Trains serve passengers for national destinations there and the last two tracks are dedicated mostly for commuter trains. As for buses, there are 21 bus stops located in The Nils Ericsson terminal. Buses serve local trips, national trips and international trips, mostly to Oslo and to Copenhagen. Additionally, on the other side of the terminal, there is a parking yard, parallel to the previously mentioned train tracks.

\section{b. Oshodi, Lagos Nigeria}

The Oshodi-terminal located in Lagos incorporates the road and rail transport modes to achieve complementarity and spatial connectedness. The Interchange comprises three terminals and shopping malls. Terminal One caters for inter-state transport activities while Terminal Two and Three caters for intra-city transport activities. The transport interchange is a combination of all 13 city and interstate motor parks located in Oshodi which is now built into three multi-storey bus terminals. The terminals are projected to serve 30,000 terminals daily. The terminals have standard facilities including: waiting area, loading bays, ticketing stands, driver lounge, parking areas, rest rooms, accessible walkways and pedestrian bridges, green parks, sky-walk to link all three terminals, surveillance tower, CCTV etc.

The terminal provides a synergy between rail networks and inland bus services. It also creating more sustainable measures to certain transport problems such as parking (with the presence of multi-level parking), proper circulation and ventilation system within the parks as well as complimentary activities (such as hotels and restaurants) for the benefit of the commuters.

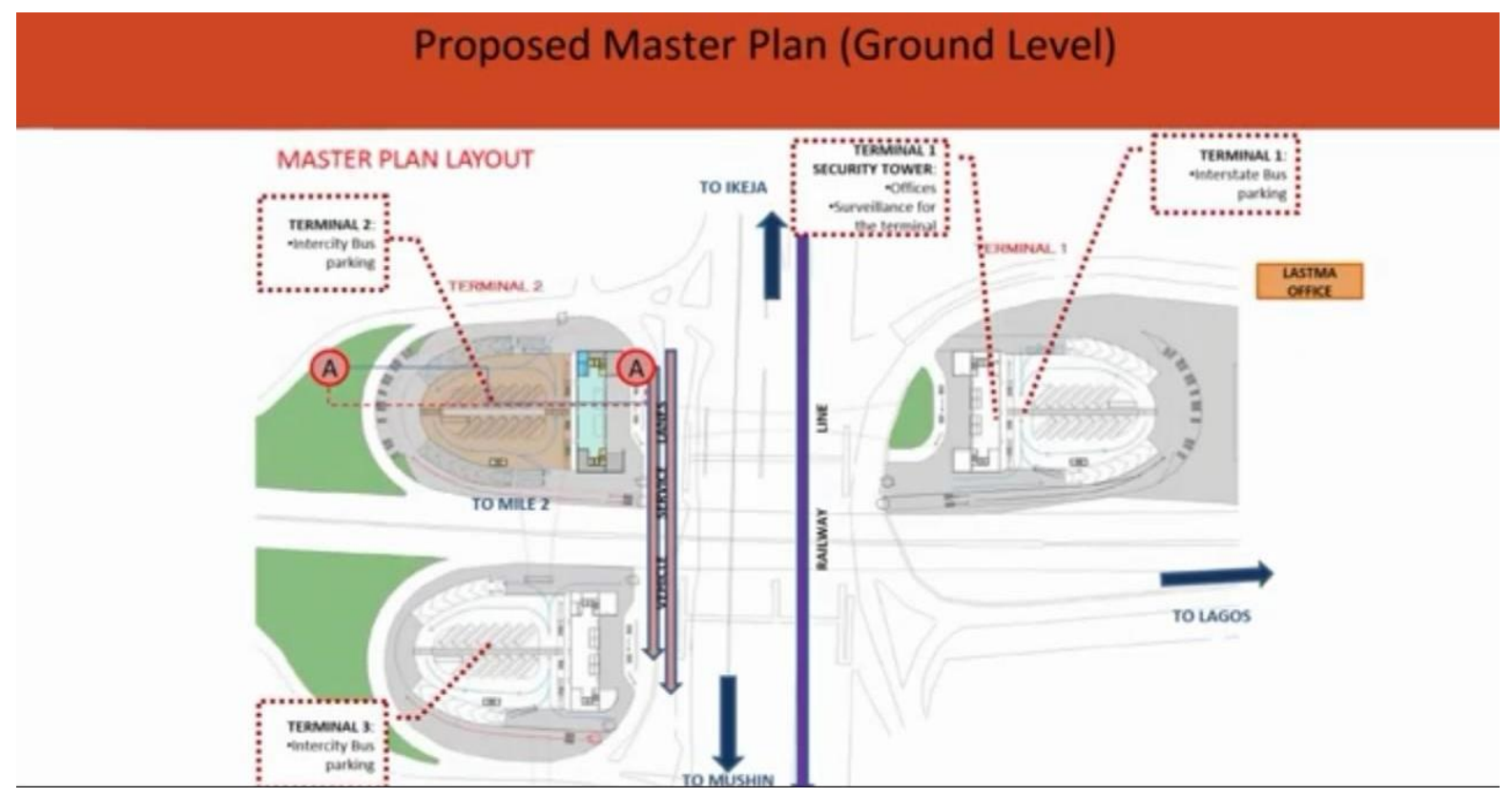

Fig 5: Master Plan (Ground Level)

Source: The Eagle Online, 2018 


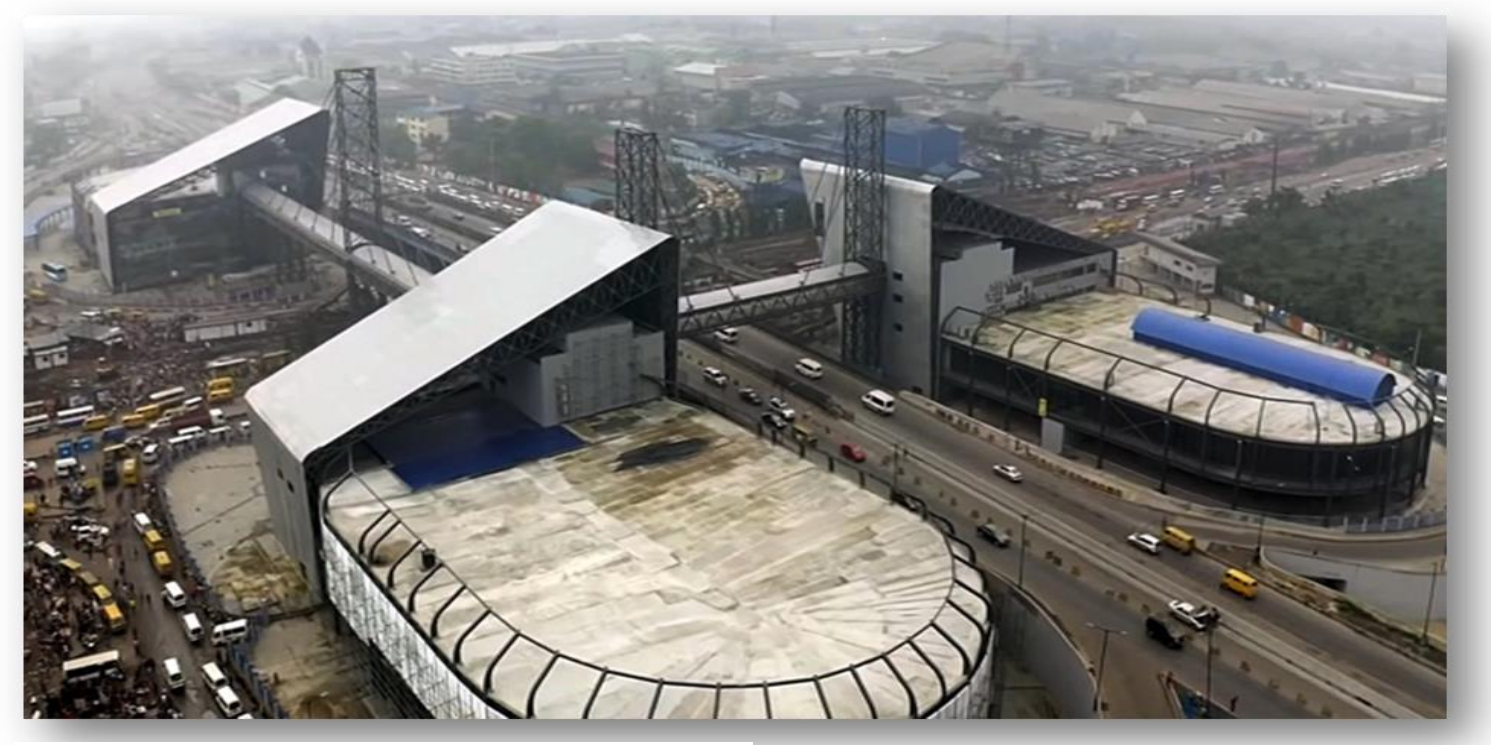

Fig 6: Oshodi Interchange, Lagos

Source: Autojosh.com

The study aims to improve the efficiency in the transport system in Port Harcourt through the incorporation of a workable multimodal transport terminal in the city. Available evidence reveals that the city still grapples with basic transport problems such as poor transport infrastructure, poor modal link (between roads, rails and ports) as well as the absence of a standardized terminal to see to the efficiency of the system. It follows therefore that concerted efforts have to be made to stem the tides in the transport industry in the city. Potential benefits derivable from proper transportation will only be fully realized if the right measures are taken towards integration of the various transport modes.

More recent effort has been made by the state government towards the delivery of certain terminals within the city, but these are largely focused on road transport to the disadvantage of other transport means. A worldwide pattern of connecting various methods of transport for a more effective and efficient endeavour is something to be imitated. There is therefore the need to propose a multimodal transit centre which is targeted at offering different transportation choices, while improving effectiveness of public transportation. Site selection is most imperative in planning for a transit centre. For an intercity transit centre where enormous amount of infrastructure are to be provided, large considerable size of site is mostly considered to avoid vertical development, modification and expansion with its attendant problems and challenges. Moreover, the site should be directly connected to the public highway, when it concerns intercity transit centre to avoid unnecessary congestion with local traffic flow.

With the capital intensive nature of the project, it is best advised that the development of the multimodal terminal should be carried out using a well defined public and private sector participatory approach. From the Gothenburg case study, it was revealed that a major success of the project was that it was owned via the 
Public-Private Partnership (PPP) model. This enables flexibility and more capital investments. Furthermore, the Government should limit its primary roles to regulatory and coordination of the activities of the diverse stakeholders in the sector. Otherwise, bureaucracy and red-tapeism would discourage and constrained the private investors from investing in the development of infrastructure that would engender the development of multimodal transport terminals.

With Port Harcourt city being one of the major hubs of economic activities south of Nigeria, the development of a multimodal terminal as well as the overall development of the multimodal transport will help increase the quantum of economic activities. Other potential benefits such as on time cargo delivery, door to door movement of cargo, reduce cargo handling, cheaper overall transportation costs, increased safety and reliability of cargo arriving at destination, etc., can be greatly realized.

\subsection{Conclusion and Recommendations}

Port Harcourt economic development has been heavily dependent upon the wealth of transportation services that are provided within the state. For this reason, fundamental changes must be made to improve transportation system and facilities within the state and Nigeria as a country. There are giant strides been made towards the advancement of multimodal transportation around the world, Nigeria should be able to tag along and not be left behind as other countries strive for improved transportation systems.

Furthermore, the Federal government and stakeholders of the Nigerian transportation system should to put laws in place guiding road transportation and also improve railway transportation system. However, the federal government should also encourage and assist states by creating an enabling environment in terms of setting in place appropriate policies and incentives to the state to develop its river transportation sector.

Lastly, transportation facilities should no longer be seen as only a passageway for commuters in Nigeria, but the full potential of transport facilities should be explored by imploring the opinions of planners of internationally successful multimodal transport facilities. Thus, the successful planning of transport facilities forms a fundamental part of the success of transport systems in Nigeria.

\section{References}

Abioye, O., Shubber, K. and Koenigsberger, J. (2016). Evaluating the role and impact of railway transport in the Nigerian economy, options and choices: Case of Nigerian Railway Corporation. AshEse Journal of Economics, 2(4), 103-113,

Ademiluyi, I. A. and Dina, O. A. (2011). The Millennium Development Goals and the Sustainable Future for Nigeria's Urban Environment: A Railway Strategy. J Hum Ecol, 33(3), 203-209.

Adesanya, A. (2010). Bringing the Nigerian Railways back on Track: Challenges and Options. Paper presented at Monthly NISER Seminar series held at the NISER conference room.

Debela F. (2013). Logistics Practice in Ethiopia. Independent thesis SUAS, Swedish University of Agriculture Sciences, 2013:09 ISSN 1654-9392, 
Etu, J. E. and Oyedepo, O. J. (2017). Effective and Efficient Multimodal Transport System: A Catalyst for Economic Development in Nigeria. 1st International Conference of the School of Management Technology (SMAT) Federal University of Technology, Akure, Nigeria 28th-31st March

Fernandez, R., Seriani, S., (2010). Pedestrian microsimulation of metro-bus interchanges; a case study in Santiago de Chile. European Transport Conference 2010. Glasgow, Scotland, UK

Gigado, U. (2015). Consequences of Port Congestion on Logistics and Supply Chain in African Ports. Journal of Developing Country Studies, 5(6),160-167

Good, Wilson and Jebbin, Maclean Felix (2015). Transportation and National Development. Journal of Economics and Sustainable Development 6(9)

Innocent, C. O. (2011). Transport Infrastructure and Mobility in Nigeria. JORIND, 9(1). ISSN 1596-8303.

Jernhusen, (2012). Gothenburg central station. [Online] Available at: http://www.jernhusen.se/Resenar/Goteborgs-Centralstation/

Odeleye A. J. (2015). The need for multimodal transport development in Nigeria Journal Geography and regional planning, vol. 8(9), pp. 239-243.

Ogunbodede E. F. (2008). Urban Road Transportation in Nigeria From 1960 To 2006: Problems, Prospects And Challenges. Ethiopian Journal of Environmental Studies and Management, 1(1), 1-12.

Oladipo, O.O. (2012). Road Transportation as Lifeline of the Economy Western Nigeria, 1920-1952. African Journal of History and Culture, 4(3), 37-45.

Oyesiku O. (2013) Institute of Transport Administration of Nigeria.

Transport Research board, (2003). Transit Capacity and quality of service manual; 2nd edition. Part 7; Stop, Stations and Terminal Capacity.

UNCTAD. (1981). United Nation Conference On a Convention of International Multimodal Transport. Geneva.

Xiao, JH, Liu, X. (2018). Development of multimodal transport in China. In: Xiao, JH, Lee, SJ, Liu, BL, et al. (eds) Contemporary logistics in China: collaboration and reciprocation. Singapore: Springer. 